\title{
Application of magnetron sputtering for producing bioactive ceramic coatings on implant materials
}

\author{
J Z SHI, C Z CHEN*, H J Y $\mathbf{U}^{\dagger}$ and S J ZHANG ${ }^{\dagger \dagger}$ \\ School of Materials Science and Engineering, ${ }^{\dagger}$ School of Mechanical Engineering, Shandong University, \\ Shandong Jinan 250061, P.R. China \\ ${ }^{\dagger \dagger}$ Mechanical Engineering Department, Jinan Vocational College, Shandong Jinan 250103, P.R. China
}

MS received 9 March 2008; revised 10 September 2008

\begin{abstract}
Radio frequency (RF) magnetron sputtering is a versatile deposition technique that can produce thin, uniform, dense calcium phosphate coatings. In this paper, principle and character of magnetron sputtering is introduced, and development of the hydroxyapatite and its composite coatings application is reviewed. In addition, influence of heat treatment on magnetron sputtered coatings is discussed. The heat treated coatings have been shown to exhibit bioactive behaviour both in vivo and in vitro. At last, the future application of the bioactive ceramic coating deposited by magnetron sputtering is mentioned.
\end{abstract}

Keywords. Radio frequency (RF); magnetron sputtering; hydroxyapatite; composite coatings; bioactive behaviour.

\section{Introduction}

Implants made of titanium or its alloys are frequently used as permanent implants after dental or bone injury. Despite the already good biocompatibility of these materials there is a need for further improvement because of the increasing age of our population, as this results in prolonged retention period of such implants in the body and a slower healing process (Wolf-Brandstetter et al 2006). The problems associated with the use of the metallic femoral stems are release of particles from wear debris, the large differences in mechanical properties between the metal implants and the natural bone, giving rise to ruptures, and the impossibility to regenerate natural bone. One approach to improve fixation between hard tissue and metal implants, and therefore, increased implant lifetime is to coat the metal surface with a bioactive material that can promote rapid bonding to natural bone. An additional advantage when coating a metallic implant with ceramics is the reduction in ion release from the metal alloy, consequently increasing corrosion resistance (Guo et al 2007). Calcium phosphates (Ca-P) are suitable materials for biomedical applications. Especially hydroxyapatite $\left(\mathrm{Ca}_{10}\left(\mathrm{PO}_{4}\right)_{6}(\mathrm{OH})_{2}, \mathrm{HA}\right)$ is widely used as a bioactive interface between the bulk metal implant and the surrounding tissue because of their close similarity to the chemical and mineral components of teeth and bones (Shtansky et al 2006).

*Author for correspondence (czchen@sdu.edu.cn)
Various methods have been used to deposit bioactive ceramic coatings such as plasma spraying, electrostatic spray deposition, pulsed laser deposition, micro-arc oxidation, sol-gel deposition and magnetron sputtering. Plasma spraying is the major method commercially available for coating implant devices with HA due to its reproducibility and economic efficiency. However, typical defects including voids, cracks and unmolten particles appear in the plasma sprayed HA coating, as a result of rapid concomitant cooling and flattening of the sprayed HA particles. Therefore, besides improvement of the plasma-spray technique, the efficacy of other deposition techniques, such as radio frequency (RF) magnetron sputtering, is being investigated for the deposition of calcium phosphate coatings (van Dijk et al 1996). The application of magnetron sputtering offers a flexible approach to surface improvement of metal implants. This technique facilitates to producing of dense and well-adhered films with controlled elemental composition (Shtansky et al 2006).

\section{Principle and character of magnetron sputtering}

In magnetron sputtering, the magnetic field can be created by permanent magnets, electromagnets or a combination of both. This configuration acts to trap electrons. Thus, in a magnetron sputtering discharge, atoms are sputtered from the cathode target by magnetically confined plasma. The target material is sputtered by the bombardment of high energy ions accelerated over the cathode sheath potential. Secondary electrons are emitted and accelerated away from the target surface as a result of the ion bombard- 
ment. These electrons play an important role in maintaining the plasma. A magnetic field confines the ionizing energetic electrons near the cathode allowing operation at high plasma densities and low pressures. This method is quite successful in producing high-quality, low-impurity films at reasonable deposition rates (Helmersson et al 2006).

Magnetron sputtering has become the process of choice for the deposition of a wide range of important coatings. Examples include hard, wear-resistant coatings, low friction coatings, corrosion resistant coatings, decorative coatings and coatings with specific optical or electrical properties (Kelly and Amell 2000). In addition, RF magnetron sputtering was used to produce calcium phosphate coatings on titanium substrates. Advantages of this deposition technique for the deposition of $\mathrm{Ca}-\mathrm{P}$ coatings are good control of coating composition, a good adhesion of the coating to the underlying substrate, and a low substrate temperature during deposition (Feddes et al 2003).

\section{Character of $\mathrm{Ca}-\mathrm{P}$ coatings}

\subsection{Structure characteristic}

Radio frequency (RF) magnetron sputtering is a versatile deposition technique that can produce thin, uniform, dense coatings that are homogeneous in structure and composition (van der Wal et al 2006a). Over the past few years, this technique has been made use of to produce thin adherent $\mathrm{Ca}-\mathrm{P}$ coatings on implants (Yonggang Yan et al 2007). But as-sputtered $\mathrm{Ca}-\mathrm{P}$ coatings are amorphous, which is generally more soluble in vitro and more degradable in vivo (Weng et al 1997). It is necessary to select an appropriate heat treatment to improve the dissolution properties of $\mathrm{Ca}-\mathrm{P}$ coatings by crystallizing the film (Yang et al 2005). Ozeki et al (2000) annealed the assputtered coatings at $800^{\circ} \mathrm{C}$ for $1 \mathrm{~h}$ in air, and found that the HA crystallite grew approximately twice after annealing. Despite the favourable result, it has to be noticed that conventional heat treatment in an electric furnace may result in the appearance of cracks in the coating because of the difference in the thermal expansion coefficient of $\mathrm{Ca}-\mathrm{P}$ and the metal substrate. This appears in weakened bond strength (van Dijk et al 1996). Therefore, it is necessary to crystallize HA films at low temperatures. Heat treatments at low temperatures and short times are able to reduce the oxidation of titanium and the diffusion of elements that influence the bond coat between the film and the titanium substrate. Yoshinari et al (1997) introduced rapid heating with infrared radiation as a suitable heat treatment for thin $\mathrm{Ca}-\mathrm{P}$ coatings. The as-sputtered amorphous $\mathrm{Ca}-\mathrm{P}$ coatings were subjected to a rapid heating with infrared irradiation. The X-ray diffraction spectra of as-coated and rapid-heated specimens are shown in figure 1. In the XRD spectrum of as-sputtered film, an amorphous calcium phosphate structure between $2 \theta=$ about $25^{\circ}$ and $34^{\circ}$ and titanium peaks at $2 \theta=35.04^{\circ}, 35.38^{\circ}$, $40 \cdot 10^{\circ}$, and $52 \cdot 96^{\circ}$ were observed. In the XRD pattern of films heat treated at 300 and $400^{\circ} \mathrm{C}$, two peaks derived from $\mathrm{CaO}$ were observed in addition to an amorphous pattern. The films heat treated at 500 and $600^{\circ} \mathrm{C}$ showed a more crystalline structure. Some hydroxyapatite peaks, $2 \theta=25.83^{\circ}(002), 31.80^{\circ}(211), 32 \cdot 14^{\circ}(112), 32 \cdot 95^{\circ}$ (300), $34.04^{\circ}(202), 46 \cdot 72^{\circ}(222)$, and $49.48^{\circ}$ (213), were visible in these XRD patterns. These measurements showed that heating at $500^{\circ} \mathrm{C}$ or higher resulted in an increase of coating crystallinity and rapid heating with infrared radiation causes phase changes in $\mathrm{Ca}-\mathrm{P}$ coatings at a lower temperature than does annealing by electric furnace.

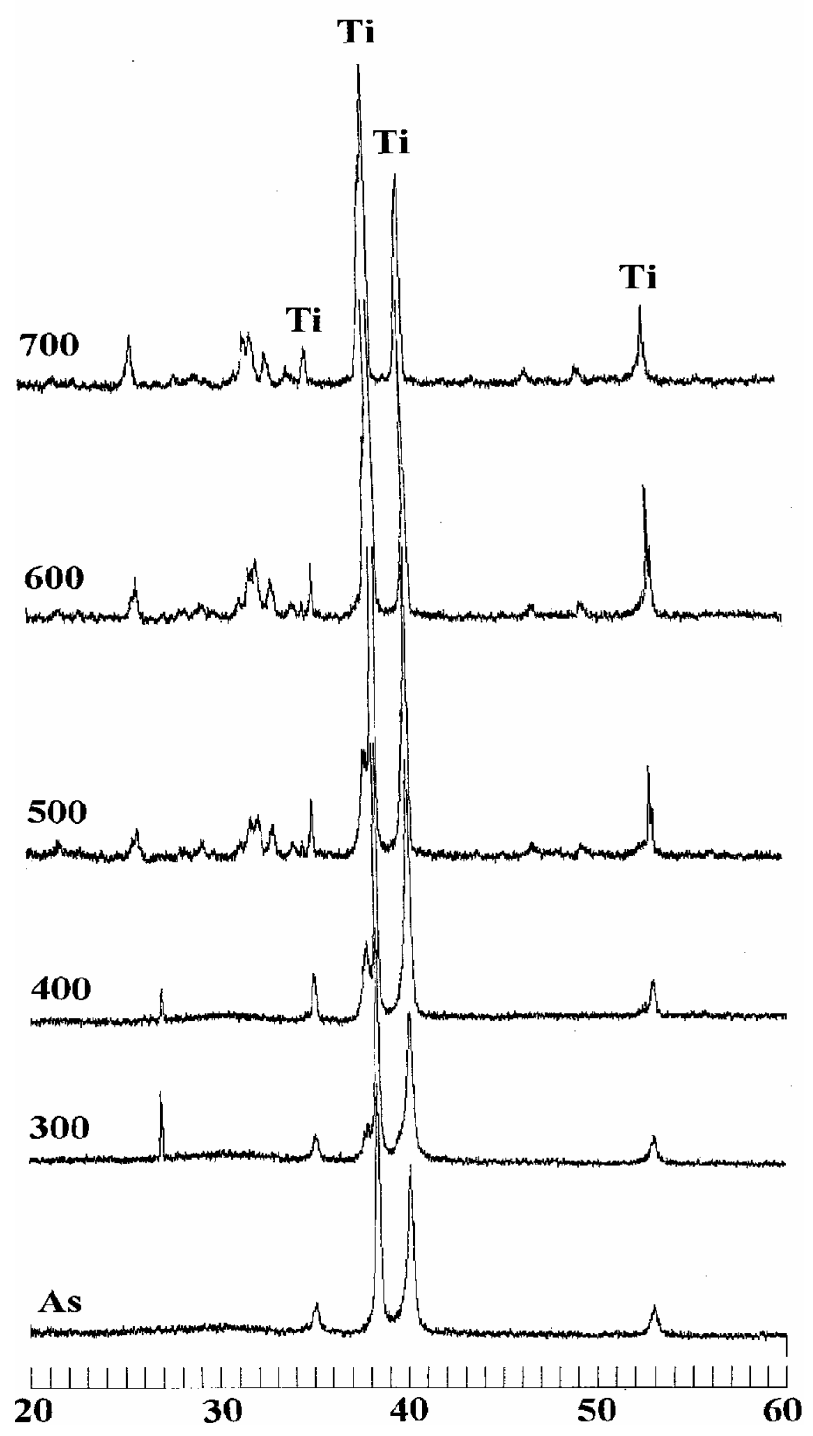

Figure 1. X-ray diffraction spectra of as-coated (untreated, As) and rapid-heated specimens. The range 300-700 represents the maximum temperature of $300,400,500,600$ and $700^{\circ} \mathrm{C}$ with the infrared radiation, respectively (Yoshinari et al 1997). 

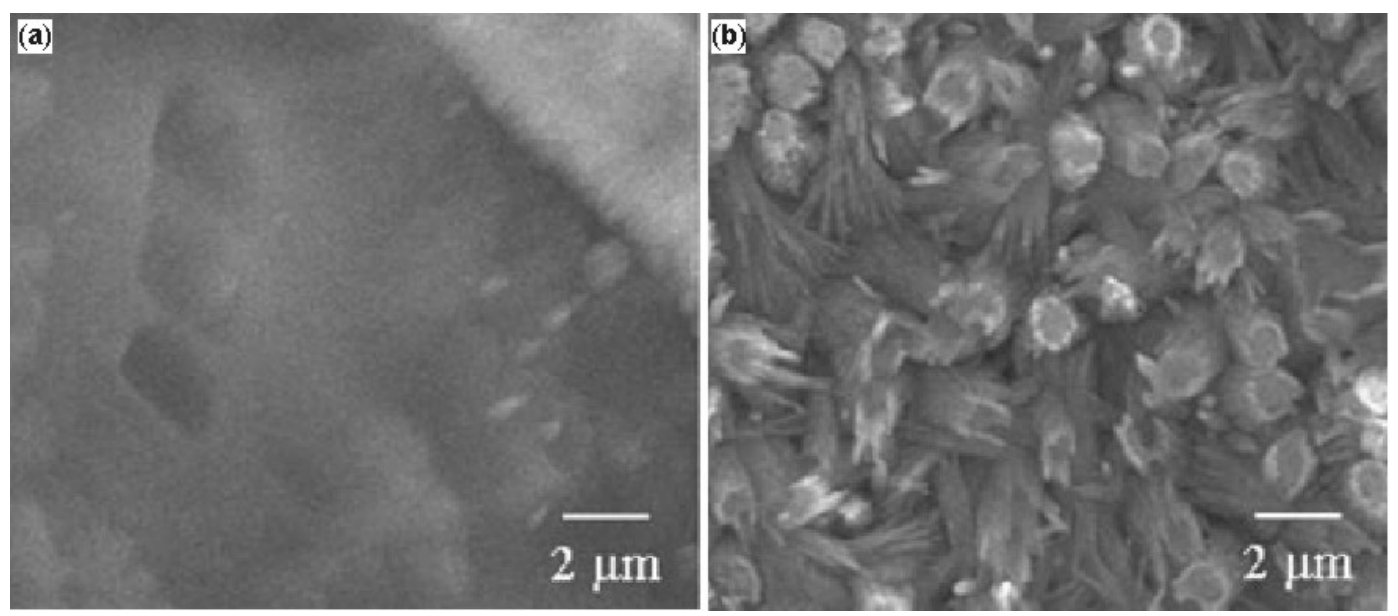

Figure 2. SEM micrographs of the sputtered films before (a) and after (b) the hydrothermal treatment (Ozeki et al 2006).

In addition, sputtered HA films could be crystallized at $110^{\circ} \mathrm{C}$ using a hydrothermal technique, without degrading the film, and the film-to-substrate adhesion strength increased by over two-fold after the treatment. Figure 2 shows SEM micrographs of the as-sputtered and hydrothermally treated films. The surface morphology changed significantly after the hydrothermal treatment. The needles in the hydrothermally treated films observed in the SEM micrographs may be needle-like HA crystals, when considered in conjunction with the XRD results reported by Ozeki et al (2006). The lattice constants of HA are $a=0.9418 \mathrm{~nm}$ and $c=0.6884 \mathrm{~nm}$. In general, HA crystal preferentially grows along the $c$-axis. The probability of deposition in the $c$-plane is higher than in the $a$-plane because the $c$-axis is considerably smaller than the $a$-axis in HA crystals (Ozeki et al 2005). Besides, the assputtered films are cytotoxic to osteoblast-like cells, but the cytotoxicity and cell differentiation of the sputtered film can be greatly improved on using the hydrothermal treatment (Ozeki et al 2006).

The surface qualities of $\mathrm{Ca}-\mathrm{P}$ implants are important factors determining the nature and degree of cellular behaviour, especially cellular attachment, proliferation and differentiation (Ong et al 1997). The biological performance of $\mathrm{Ca}-\mathrm{P}$ coatings can be improved after heat treatment. The treated $\mathrm{Ca}-\mathrm{P}$ coatings will be shown to have a good biological response, both in vivo and in vitro.

\subsection{In vitro study}

The bioactivity of Ca-P is often connected to the formation of a thin mineralized interlayer between the coating and bone tissue that has attached to the coating. Thus, in order to understand bioactivity, it is important to study the early stages of precipitation of $\mathrm{Ca}-\mathrm{P}$ from the surrounding medium and to determine the role of the surface composition and structure, as well as the properties of the fluid boundary layer. We can describe the precipitation of $\mathrm{Ca}^{-}$ $\mathrm{P}$ crystals on the surface of these coatings from simulated body fluids (SBFs; SBFs with $x$ times the $\mathrm{Ca}^{2+}$ and $\mathrm{PO}_{4}^{3-}$ concentrations are called SBFx) (van der Wal et al 2006b). With RF magnetron sputter technique coatings can be produced that vary in $\mathrm{Ca} / \mathrm{P}$ ratio as well as in structural appearance (Hulshoff et al 1998). All heat-treated coatings appeared to be stable in simulated body fluid (Yonggang Yan et al 2006). Furthermore, the coatings with a $\mathrm{Ca} / \mathrm{P}$ ratio of $\sim 1.6$ can allow the formation of a $\mathrm{Ca}-\mathrm{P}$ precipitate after an induction period of 40-60 min when immersed in $\mathrm{SBF}_{2}$. Figure 3 shows the electron micrographs of Ca-P coated samples after immersion in $\mathrm{SBF}_{2}$ for $20,40,50$ and $90 \mathrm{~min}$ ((a), (b), (c), and (d), respectively). In $\mathrm{SBF}_{2}$, the formation of crystals is preceded by an induction period in which sediments from the solution are found to adhere to the coating surface. The presence of the sediments seems to be correlated to the nucleation and growth of $\mathrm{Ca}-\mathrm{P}$ precipitates from ions from the solution (van der Wal et al 2005).

However, the mechanisms involved in the formation of the interface between the coating and bone may differ drastically from those in pure inorganic SBF. Besides the physico-chemical interactions, adsorption of proteins to the surface and substrate specific cell activity also influences the structure of the interface under biological conditions (van der Wal et al 2006a). So we can obtain more information on the biological behaviour of these coatings by way of in vitro assessments in bone cell culture. $\mathrm{Ca}-\mathrm{P}$ coated substrates supported the formation of mineralized globuli. On the other hand, compared with Ti disks, the deposited layer was significantly thicker and was associated with a rich, fibrous collagen matrix. As shown in figure 4 , cells on the coated substrates were surrounded by extracellular matrix (ECM) with collagen fibres embedded in crystallized, needle-shaped structures (Hulshoff et al 1998). Indeed, magnetron-sputtered Ca-P 
coating can induce apatite deposition and stimulate the formation of mineralized ECM.

In addition, $\mathrm{Xu}$ et al (2005) deposited HA coatings on Ti-6Al-4V using the RF magnetron co-sputtering deposition method and investigated the associated biocompatibility responses from the synthesized HA films. Cell growth and replication can also be seen in the SEM micrographs shown in figure 5. The cells show signs of attachment to the HA crystals and cellular differentiation after two-day incubation. Then the cells consistently grow in size throughout the entire duration of the cell culture experiment. After eight days, a thick layer of extracellular matrix and bone nodules are formed. The cell culture experiments suggest that the HA coatings are indeed cytocompatible.

\subsection{In vivo study}

Despite the above favourable results, the question still arises whether the performed experiments are of any relevance for the in vivo bone situation. In an organ culture the architecture of the original tissue is maintained better and further development is as occurs in vivo. Depo-
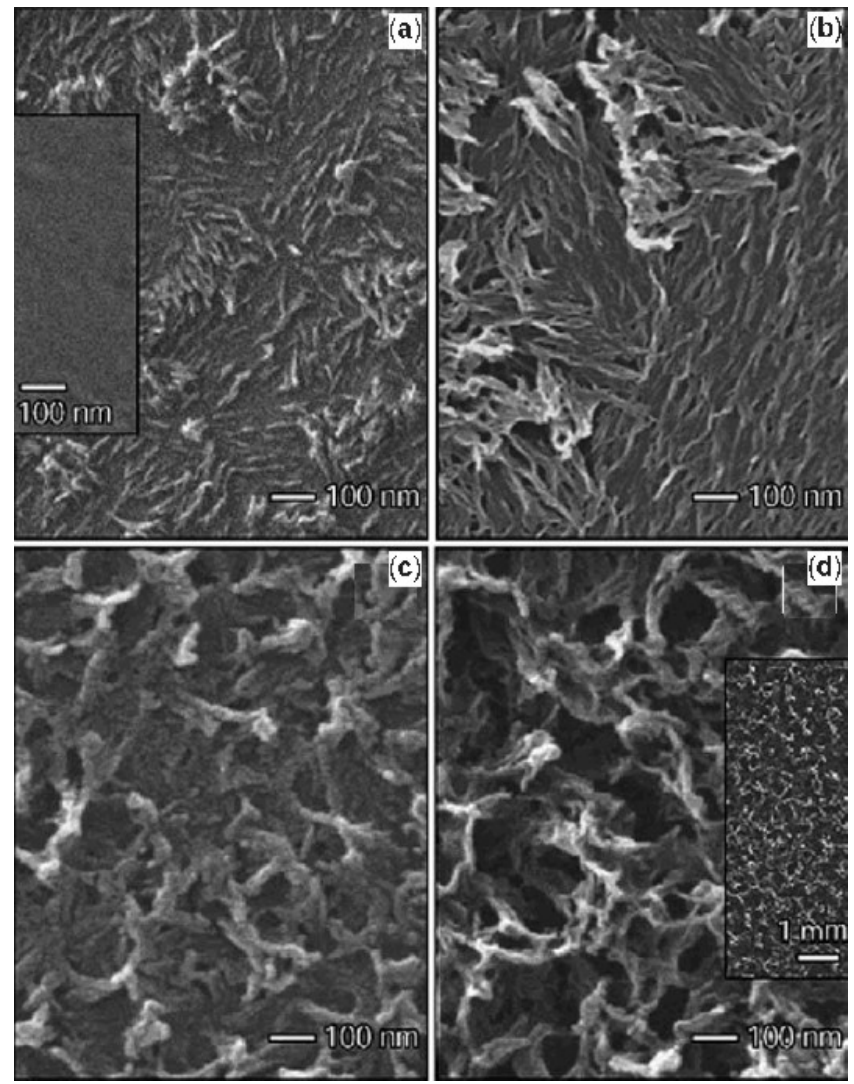

Figure 3. SEM micrographs of $\mathrm{Ca}-\mathrm{P}$ samples after immersion in $\mathrm{SBF}_{2}$ for different periods of time: (a) $20 \mathrm{~min}$, (b) $40 \mathrm{~min}$, (c) $50 \mathrm{~min}$ and (d) $90 \mathrm{~min}$. The top left inset shows a nonimmersed reference. The bottom right inset shows a sample after 90 min of immersion at a lower magnification (van der Wal et al 2005). sition of a sputtered $\mathrm{Ca}-\mathrm{P}$ coating on an implant has a beneficial effect on the bone response to this implant during the healing phase. Wolke et al (2003) produced $\mathrm{Ca}-\mathrm{P}$ coatings on roughened titanium discs and implanted the discs into the rabbits. Histological evaluation (figure 6) revealed that the tissue response to all coated implants was very uniform at 8 and 12 weeks of implantation. A very thin connective tissue capsule surrounded all implants. The capsule was usually free of inflammatory cells. At the interface, there was a close contact between the capsule and implant surface and no inflammatory cells were seen.

After implantation, the $\mathrm{Ca}-\mathrm{P}$ coating is dissolved locally and a granular precipitate is deposited gradually. Dissolu-

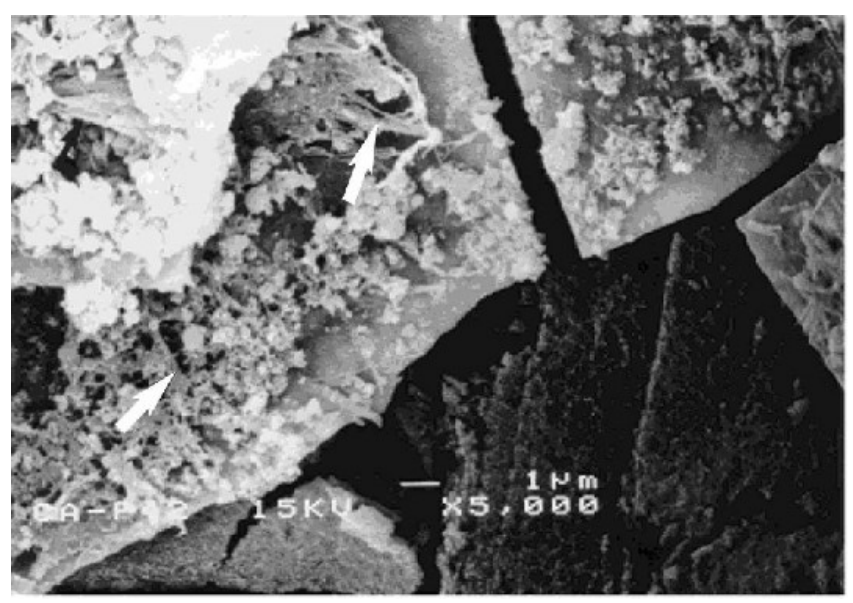

Figure 4. SEM picture showing $\mathrm{Ca}-\mathrm{P}$ substrate after 16 days of incubation. Besides globular accretions, a rich fibrous collagen matrix is associated with the osteoblast like cells. Ca-P substrate: an abundance of ECM with collagen fibres (arrows) can be observed (Hulshoff et al 1998).

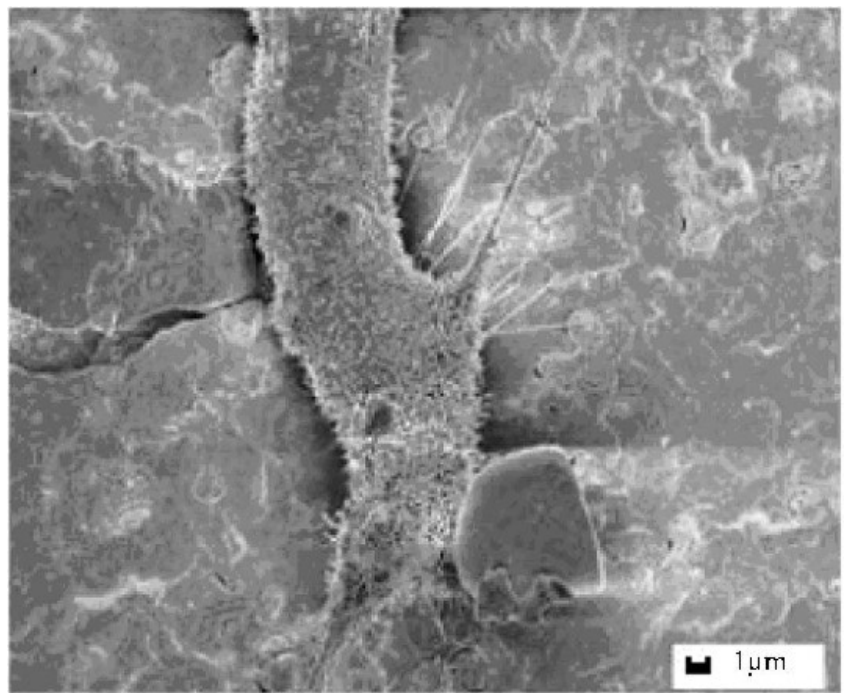

Figure 5. SEM image of osteoblast cells after two-day incubation (Xu et al 2005) 
tion/precipitation-mediated events influence this formation of biological apatite on the implant surface. The partial dissolution of the sputter coatings causes an increase in the local concentrations of calcium and phosphate ions, thereby increasing the degree of saturation in the microenvironment. This will facilitate the precipitation of a stable calcium phosphate phase which incorporates other ions and organic macromolecules from the biological
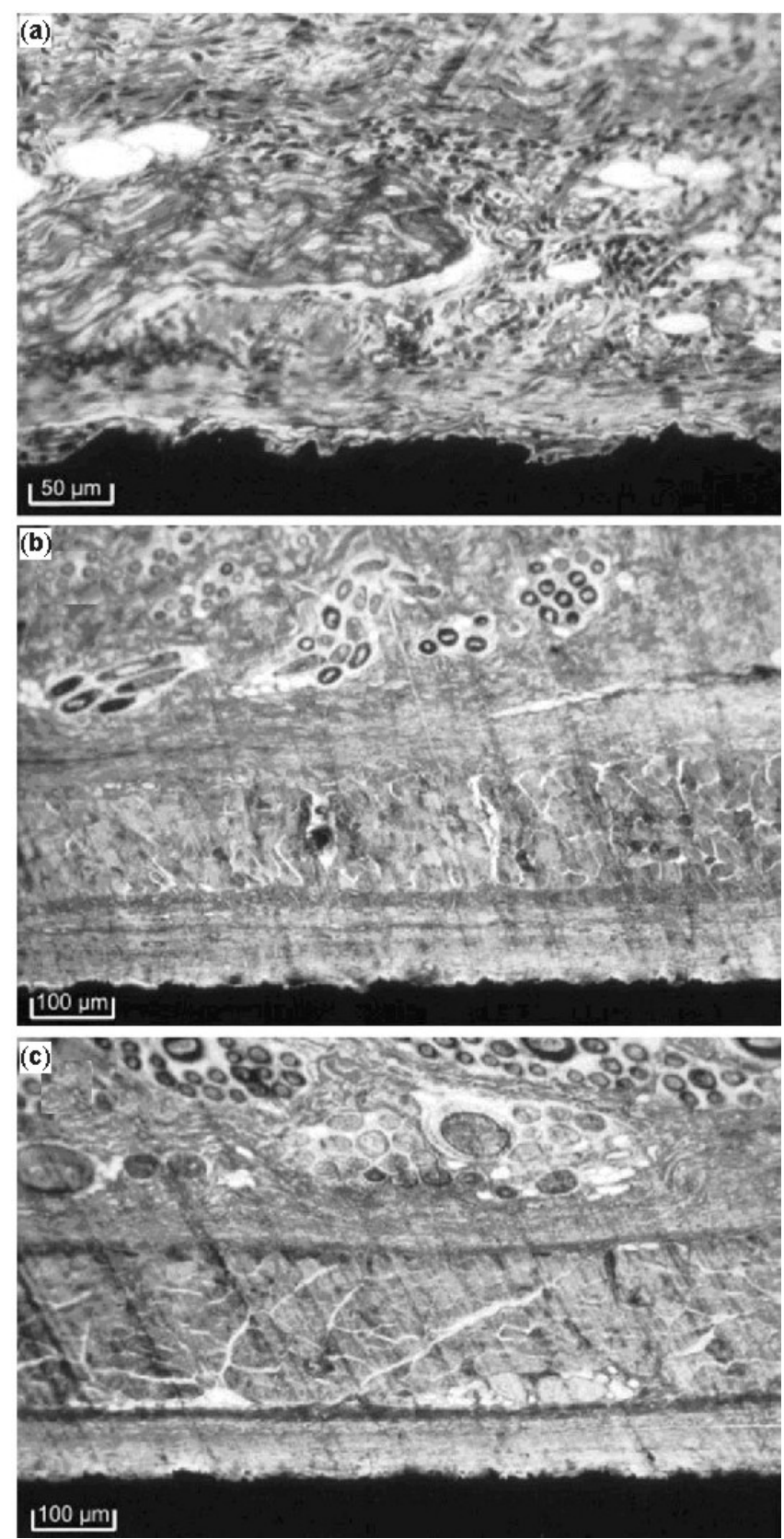

Figure 6. A light microscopical section of a coated specimen after 1 week of implantation showing a moderately thick loose connective tissue capsule, containing inflammatory cells and blood vessels surrounding the implant (a). After 4 weeks the capsule was almost free of inflammatory cells (b). At 12 weeks of implantation the implants were surrounded with a thin connective tissue capsule (c) (Wolke et al 2003). fluids (Wolke et al 1998a). These organic macromolecules are absorbed first on the implant surface. Figure 7 shows a network of randomly oriented collagen fibres appeared to be attached to the disks after 1 week of implantation (Wolke et al 1998b). After few weeks, apatite formation occurred on the surface of the $\mathrm{Ca}-\mathrm{P}$ coating and was strongly attached (figure 8) (Wolke et al 1998a).

On the other hand, the bone-bonding strength of sputtering-coating was proven to be higher than that of noncoating. Ozeki et al (2001) implanted the HA coating titanium columns in femora of dogs and carried out pushout testing after 2, 4 and 12 weeks of implantation using a testing machine. Figure 9 showed push-out strength

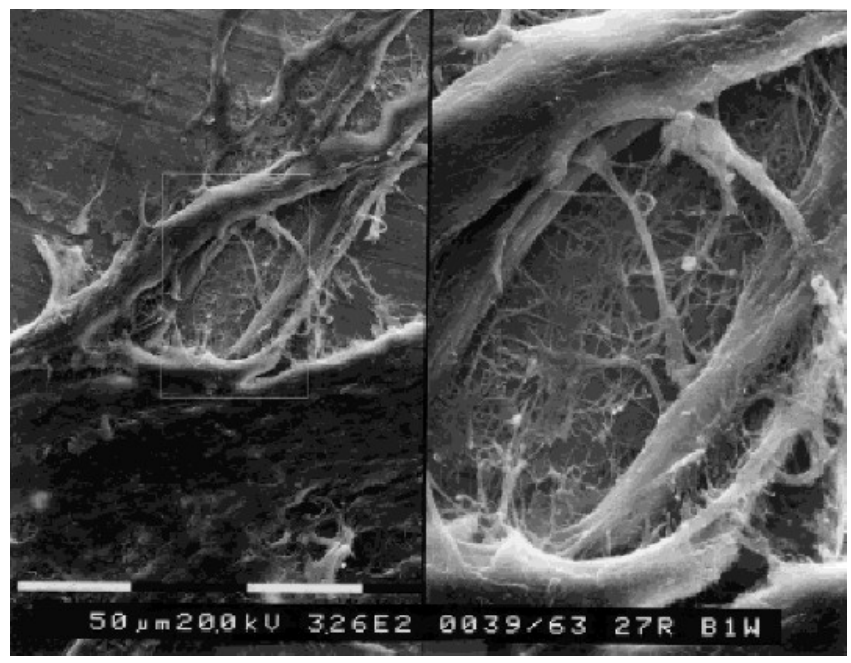

Figure 7. SEM micrograph of the retrieved disk after 1 week of implantation. The surface was partially covered with a multilayer of cells. Under this layer a network of randomly oriented collagen fibres appeared to be attached to the disks (Wolke et al 1998b).

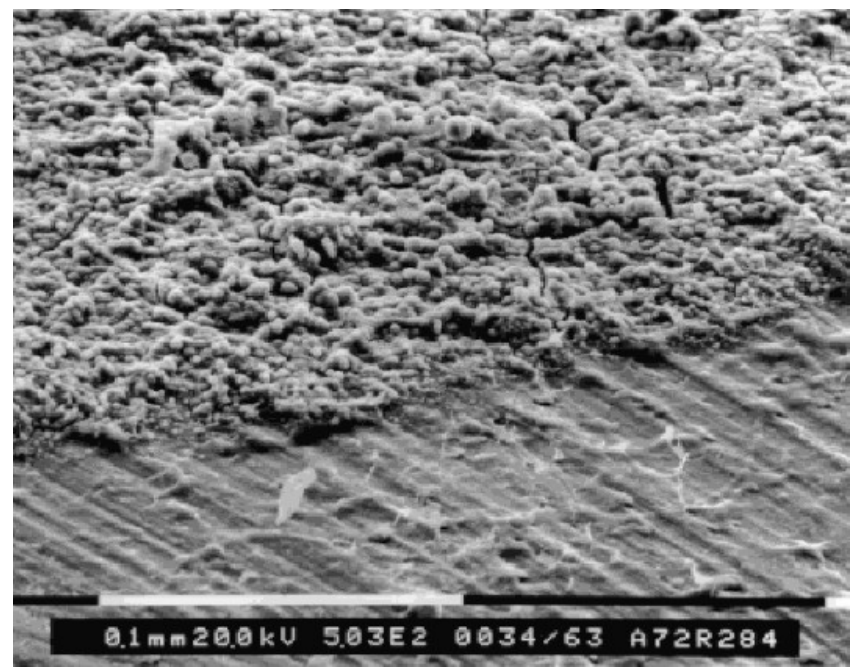

Figure 8. SEM micrograph of the $\mathrm{Ca}-\mathrm{P}$ precipitate on a heattreated coating 4 weeks after implantation (Wolke et al 1998a). 
corresponding to bone-bonding strengths. The strength in sputtering-HA-coating and non-coating was 3.5 and $1 \mathrm{MPa}$ at 12 weeks, respectively.

\section{Character of composite coatings}

\section{$4.1 \mathrm{HA} / \mathrm{Ti}$ composite coatings}

The most popular coating among the entire calcium phosphate family was hydroxyapatite (HA) because of its chemical stability and osteoconductivity. However, it was found that the bonding between the HA coating and metallic substrate was not strong. Even highly crystalline monolithic HA coating was largely delaminated in 3 weeks after immersion in SBF (Ding et al 1999a).

One approach to improve the bond strength of an HA coating onto metallic substrate was the deposition of a composite coating, wherein a metallic phase was introduced to serve as either an intermediate layer or a second (continuous or dispersed) phase in the HA matrix. The HA/Ti coatings sputtered from targets comprising of $10 \mathrm{vol} \%$ or more Ti appeared almost in tact, and their adhesion strengths, which were all higher than $60 \mathrm{MPa}$, did not change much even after 14 weeks of immersion (Ding et al 1999a, b).

In addition, a new biocompatible multi-layered coating was developed by alternately depositing Ti and HA layers on $\mathrm{Ti}-6 \mathrm{Al}-4 \mathrm{~V}$ substrates using radio frequency magnetron-assisted sputter processing, combining the advantages of both thin coating and functionally graded coating concepts. XRD results of the multi-layered coating (figure 10) revealed that the diffraction peaks of apatite between $2 \theta=25^{\circ}$ and $35^{\circ}$ apparently remained similar throughout the immersion test (up to 14 weeks), particularly observing the strong (002) preferred orientation. The multi-layered coatings not only retained a high adhesion strength value (>60 MPa), but also exhibited a better immersion behaviour (Ding 2003).

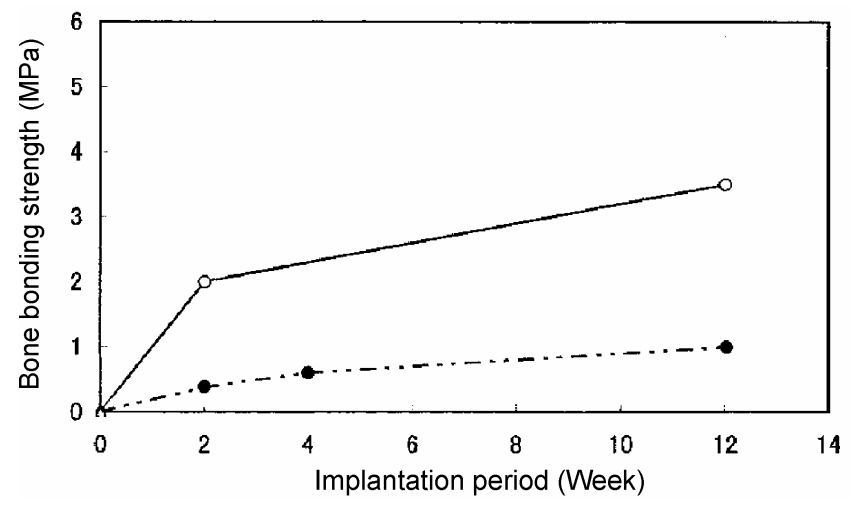

Figure 9. Bone bonding strength in various coating techniques during implantation period: • non-coating; o sputtering (Ozeki et al 2001)

\subsection{Other composite coatings}

Silicon is known to be essential in the early stages of bone mineralization and soft tissue development. In order to take advantage of the benefits of the enhanced biological effects of $\mathrm{Si}$, it is thought that incorporating $\mathrm{Si}$ into HA will improve the bioactivity of the ceramic (Porter et al 2004; Thian et al 2005a, b, 2006a, b, c, 2007). The application of magnetron co-sputtering to deposit Si-HA as thin films on metallic surfaces allows flexibility to control the level of Si in HA whilst retaining its phase purity. The ability of these Si-HA films to support the growth of human osteoblast-like (HOB) cells was investigated. Confluent and well-spread cells existed on the film surfaces after 20 days of culture. Extracellular matrix (ECM) with the appearance of bone-like nodules, was also produced (figure 11). Based on the excellent bioactivity of magnetron co-sputtered Si-HA thin films, it is suggested that this material can be applied as a bioactive coating on metal implants to enhance fixation (Thian et al 2005a).

Some silicate ceramics, for instance $\mathrm{CaO}-\mathrm{SiO}_{2}$ and $\mathrm{CaO}-\mathrm{MgO}-2 \mathrm{SiO}_{2}$, have also been reported to possess good bioactivity and biocompatibility (Shtansky et al 2006). Mardare et al (2003) deposited thin films of bioactive glass-ceramics by RF magnetron sputtering, and samples kept in simulated body fluid showed an apatite-

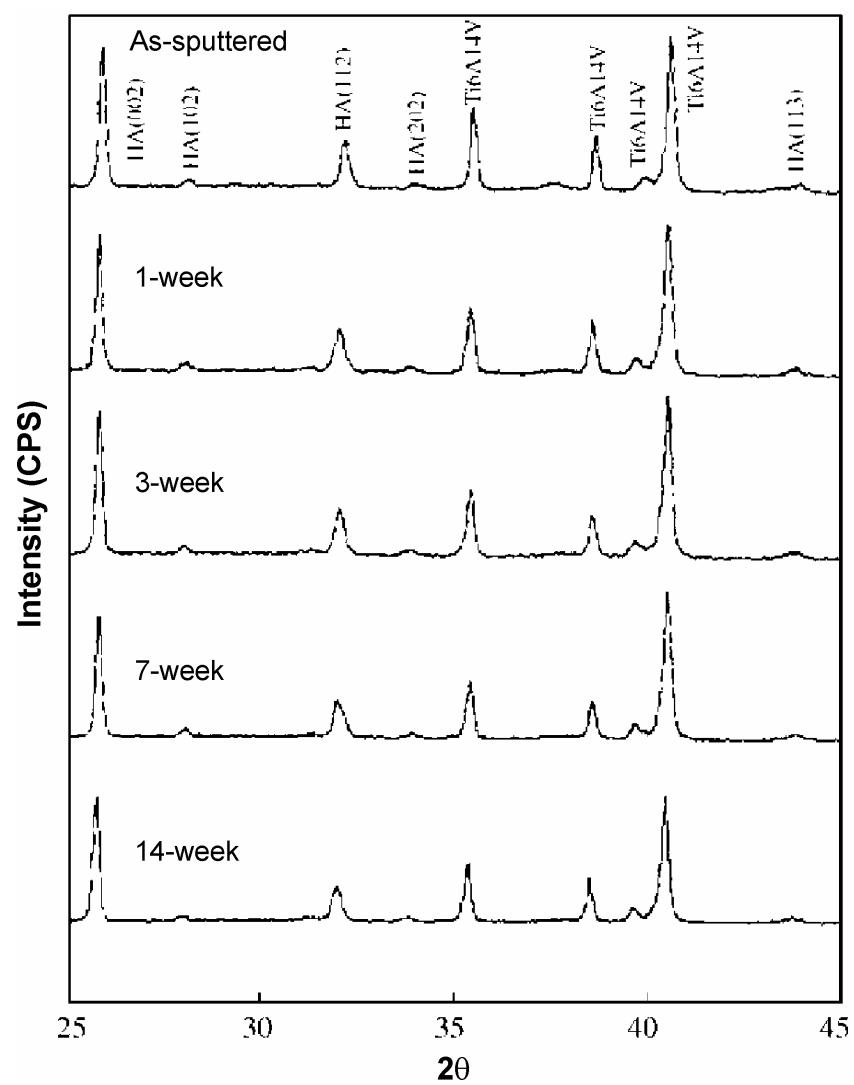

Figure 10. XRD patterns of as-sputtered and immersed coatings (Ding 2003) 


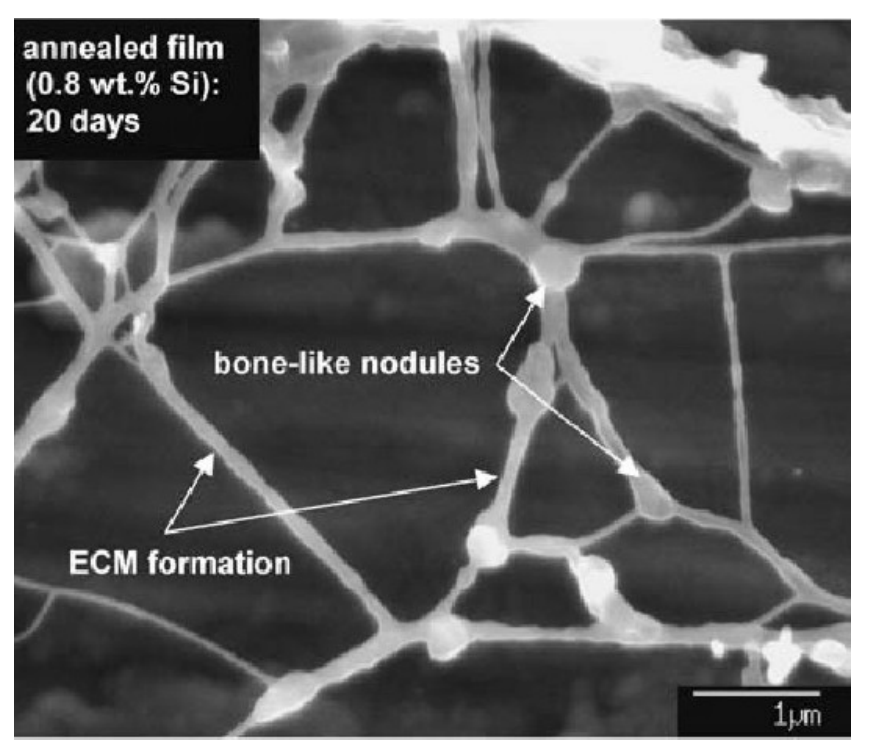

Figure 11. Images showing formation of extracellular matrix (ECM) at culture day 20 (SEM) (Thian et al 2005a).

like layer, suggesting that the films are bioactive. On the other hand, bioactive glasses (BG) meet three criteria for ideal biomedical materials: excellent osteoconductivity and bioactivity, ability to deliver cells, and controllable biodegradability (Chen et al 2006). These advantages make bioactive glasses promising coating materials for bone tissue engineering. 45S5-coated implants exhibited greater bone ingrowth compared with HA-coated implants, and they maintained their mechanical integrity over time (Wheeler et al 2001). And the biological performance of the BG/HA sputter coating is more excellent (Wolke et al 2005).

Zirconia $\left(\mathrm{ZrO}_{2}\right)$, especially for yttria stabilized zirconia (YSZ), having the attributes of high strength and stressinduced phase transformation toughening, has been used to reinforce the hydroxyapatite coatings and to improve the bond strength of the HA coatings. The bond strength of HA (+YSZ)/Ti6Al4V composite coatings prepared by RF magnetron sputter technique can be reached to 59.6 MPa (Zhao et al 2006a, b).

\section{Conclusions}

Magnetron sputtering of calcium phosphate coating is a promising method for forming a biocompatible ceramic coating. It is possible to deposit a desired $\mathrm{Ca}-\mathrm{P}$ coating or its composite coatings by choosing the appropriate deposition parameters. These coatings have shown to exhibit bioactive behaviour both in vivo and in vitro. Therefore, the coated implants have an outstanding potential for supporting bone material ingrowth and remodeling in orthopedic and dental applications.

\section{Acknowledgements}

This work is part of research programs financed by the Promotional Fund of Scientific Research for Excellent Middle-aged and Youthful Scientists of Shandong Province (Project No. 02BS056) and Department of Health of Shandong Province (Project No. HZ027).

\section{References}

Chen Q Z, Thompson I D and Boccaccini A R 2006 Biomaterials 272414

Ding S-J 2003 Biomaterials 244233

Ding S-J, Ju C-P and Lin J-H C 1999a J. Biomed. Mater. Res. 47551

Ding S-J, Ju C-P and Lin J-H C 1999b J. Biomed. Mater. Res. 44266

Feddes B, Wolke J G C and Jansen J A 2003 J. Appl. Phys. 93 662

Guo X, Gough J and Xiao P 2007 J. Biomed. Mater. Res. A80 24

Helmersson U, Lattemann M, Bohlmark J, Ehiasarian A P and Gudmundsson J T 2006 Thin Solid Films 5131

Hulshoff J E G, van Dijk K, de Ruijter J E, Rietveld F J R, Ginsel L A and Jansen J A 1998 J. Biomed. Mater. Res. 40464

Kelly P J and Amell R D 2000 Vacuum 56159

Mardare C C, Mardare A I, Fernandes J R F, Joanni E, Pina S C A, Fernandes M H V and Correia R N 2003 J. Eur. Ceram. Soc. 231027

Ong J L, Raikar G N and Smoot T M 1997 Biomaterials 18 1271

Ozeki K, Yuhta T, Aoki H, Nishimura I and Fukui Y 2000 Biomed. Mater. Eng. 10221

Ozeki K, Yuhta T, Aoki H, Nishimura I and Fukui Y 2001 Biomed. Mater. Eng. 1163

Ozeki K, Aoki H and Fukui Y 2005 J. Mater. Sci. 402837

Ozeki K, Aoki H and Fukui Y 2006 J. Biomed. Mater. Res. A76 605

Porter A E, Rea S M, Galtrey M, Best S M and Barber Z H 2004 J. Mater. Sci. 391895

Shtansky D V et al 2006 Surf. Coat. Technol. 2014111

Thian E S, Huang J, Best S M, Barber Z H and Bonfield W 2005a J. Mater. Sci.: Mater. Med. 16411

Thian E S, Huang J, Best S M, Barber Z H and Bonfield W 2005b Biomaterials 262947

Thian E S, Huang J, Best S M, Barber Z H and Bonfield W 2006a J. Biomed. Mater. Res. B: Appl. Biomater. B76 326

Thian E S, Huang J, Vickers M E, Best S M, Barber Z H and Bonfield W 2006b J. Mater. Sci. 41709

Thian E S, Huang J, Best S M, Barber Z H, Brooks R A, Rushton N and Bonfield W 2006c Biomaterials 272692

Thian E S, Huang J, Best S M, Barber Z H and Bonfield W 2007 Mater. Sci. Eng. C27 251

van Dijk K, Schaeken H G, Wolke J G C and Jansen J A 1996 Biomaterials 17405

van der Wal E, Vredenberg A M, Ter Brugge P J, Wolke J G C and Jansen J A 2006a Biomaterials 271333

van der Wal E, Oldenburg S J, Heij T, Denier van der Gon A W, Brongersma H H, Wolke J G C, Jansen J A and Vredenberg A M 2006b Appl. Surf. Sci. 2523843 
van der Wal E, Wolke J G C, Jansen J A and Vredenberg A M 2005 Appl. Surf. Sci. 246183

Weng J, Liu Q, Wolke J G C, Zhang D and de Groot K 1997 J. Mater. Sci. Lett. 16335

Wheeler D L, Montfort M J and McLoughlin S W $2001 \mathrm{~J}$. Biomed. Mater. Res. 55603

Wolf-Brandstetter C, Lode A, Hanke T, Scharnweber Di and Worch H 2006 J. Biomed. Mater. Res. A79 882

Wolke J G C, de Groot K and Jansen J A 1998a J. Biomed. Mater. Res. 39524

Wolke J G C, de Groot K and Jansen J A 1998b J. Biomed. Mater. Res. B: Appl. Biomater. 43270

Wolke J G C, van der Waerden J P C M, Schaeken H G and Jansen J A 2003 Biomaterials 242623
Wolke J G C, Vandenbulcke E, van Oirschot B and Jansen J A 2005 Key Eng. Mater. 284-286 187

$\mathrm{Xu} \mathrm{S}$, Long J D, Sim L, Diong C H and Ostrikov K 2005 Plasma Process. Polym. 2373

Yang Y, Kim K-H and Ong J L 2005 Biomaterials 26327

Yonggang Yan, Wolke J G C, Yubao Li and Jansen J A 2006 J. Biomed. Mater. Res. A76 744

Yonggang Yan, Wolke J G C, Yubao Li and Jansen J A 2007 J. Mater. Sci.: Mater. Med. 181061

Yoshinari M, Hayakawa T, Wolke J G C, Nemoto K and Jansen J A 1997 J. Biomed. Mater. Res. 3760

Zhao Y T, Cheng X N and Dai Q X 2006a J. Inorg. Mater. 211237

Zhao Y T, Zhang Z, Dai Q X, Lin D Y and Li S M 2006b Surf. Coat. Technol. 2005354 